\title{
ANÁLISE PSICOLINGUÍSTICA E COGNITIVO-LINGUÍSTICA DAS PROVAS DE HABILIDADES METALINGUÍSTICAS E LEITURA REALIZADAS EM ESCOLARES DE 2ª A 5ª SÉRIE
}

\author{
Psycholinguistic and cognitive-linguistic analysis \\ of the metalinguistic skills and reading proofs in students \\ from $2^{\text {nd }}$ to $5^{\text {th }}$ grades of elementary education
}

\author{
Vera Lúcia Orlandi Cunha ${ }^{(1)}$, Simone Aparecida Capellini (2)
}

\begin{abstract}
RESUMO
Objetivos: analisar o desempenho de escolares de $2^{\mathrm{a}}$ a $5^{\mathrm{a}}$ série do ensino fundamental em provas de habilidades metalinguísticas e leitura segundo critérios psicolinguísticos e cognitivo-linguísticos e verificar similaridade e diferenças entre as análises. Métodos: participaram 120 escolares de $2^{\underline{a}}$ a $5^{\underline{a}}$ série do ensino municipal, de ambos os gêneros, na faixa etária de sete a 12 anos de idade, divididos em 4 grupos de 30 escolares de cada série. Os escolares foram submetidos à aplicação de provas de habilidades metalinguísticas e de leitura. Resultados: houve diferença estatisticamente significante entre os grupos nas habilidades metalinguísticas, nas regras de decodificação de palavras reais e pseudopalavras para todas as variáveis na leitura de palavras reais, com exceção do erro tipo Recusas, com médias superiores para Tentativas de Som Mal Sucedidas e Falha na Aplicação de Regras Ortográficas, indicando que esses tipos de erros foram os de maior ocorrência. Na leitura de pseudopalavras houve diferença estatisticamente significante em Tentativas de Som Mal Sucedidas, indicando que os escolares apresentaram desempenho inferior na decodificação de palavras que exigiram a utilização de informação fonológica. Conclusão: a adoção de critérios psicolinguísticos ou cognitivo-linguísticos na avaliação da leitura de palavras e pseudopalavras juntamente com a avaliação das habilidades metalinguísticas fornecem subsídios para a compreensão de como o escolar vem processando os complexos princípios do sistema de escrita do português do Brasil, além de dar o suporte necessário à compreensão das dificuldades específicas apresentadas pelos escolares, orientando o profissional fonoaudiólogo em relação aos objetivos precisos no seu atendimento.
\end{abstract}

DESCRITORES: Leitura; Avaliação; Aprendizagem; Linguística; Educação

\section{INTRODUÇÃO}

A capacidade da leitura de palavras envolve processos distintos, como a informação visual, fonológica e ortográfica da palavra. Para que adquira a

(1) Fonoaudióloga; Mestre e Doutoranda em Educação na Faculdade de Filosofia e Ciências da Universidade Estadual Paulista, FFC-UNESP, Marília, SP.

(2) Fonoaudióloga; Docente do Departamento de Fonoaudiologia e do Programa de Pós-Graduação em Educação da Faculdade de Filosofia e Ciências da Universidade Estadual Paulista, FFC-UNESP, Marília, SP, Brasil; Doutora em Ciências Médicas pela Universidade Estadual de Campinas.

Conflito de interesses: inexistente leitura, a criança necessita passar por todos estes processos, especialmente entender que as letras representam os fonemas, isto é, que estas correspondem a segmentos sonoros menores, compreendendo, assim, o princípio alfabético da correspondência grafofonêmica. Essa noção é fundamental para a aquisição da leitura em uma língua cujo sistema de escrita é alfabético ${ }^{1,2}$.

Para adquirir a compreensão do princípio alfabético, é necessário que a criança desenvolva a habilidade fonológica. Esta habilidade permite identificar e manipular as unidades da palavra, podendo-se distinguir dois tipos de análise, dependendo da unidade, se silábica ou fonêmica. Esta habilidade 
é definida como consciência fonológica e está relacionada à habilidade de refletir e manipular os segmentos da fala, abrangendo, além da capacidade de reflexão (consultar e comparar), a capacidade de operar com rimas, aliteração, sílabas e fonemas (contar, segmentar, unir, adicionar, suprimir, substituir e transpor) ${ }^{3}$.

A habilidade fonológica desenvolve-se em um contínuo de etapas evolutivas sucessivas que resultam do desenvolvimento e amadurecimento biológico em constantes trocas com o meio ou contexto. A consciência e manipulação de fonemas são adquiridas à medida que os escolares vão representando-as durante suas tentativas de escrever palavras familiares e não familiares ${ }^{4-7}$.

O desenvolvimento da habilidade fonológica será favorecido à medida que a criança for submetida a complexas tarefas linguísticas, como o aprendizado da leitura. Dentre os aspectos desta evolução, a habilidade para a sílaba, que se desenvolve em etapa pré-escolar, passa para o nível do fonema, mais complexo, que é adquirido no período escolar concomitantemente com a aprendizagem formal da leitura e da escrita ${ }^{7}$.

Diversos estudos anteriores revelaram a existência de uma relação de reciprocidade entre consciência fonológica e aquisição da leitura e escrita. Esses autores explicam que os estágios iniciais da consciência fonológica contribuem para o estabelecimento dos estágios iniciais do processo de leitura, e estes, por sua vez, contribuem para o desenvolvimento de habilidades fonológicas mais complexas. Desta forma, enquanto a consciência de alguns segmentos sonoros (suprafonêmicos) parece desenvolver-se com a aquisição da linguagem oral, a consciência fonêmica parece exigir experiência específica em atividades que possibilitam a identificação da correspondência entre os elementos fonêmicos da fala e os elementos grafêmicos da escrita. Esse processo de associação fonema-grafema exige um desenvolvimento de análise e síntese de fonemas. Para se chegar à descoberta do fonema, torna-se necessário adquirir e desenvolver a consciência fonológica e a manipulação cognitiva das representações neste nível; o contato com a linguagem escrita possibilita 0 desenvolvimento desta capacidade, assim como esse desenvolvimento auxilia nos níveis mais avançados de leitura e escrita ${ }^{2,8-16}$.

Em estudos anteriores, foi constatada a existência de uma forte relação entre as habilidades de processamento fonológico, mais especificamente a consciência fonológica, e a habilidade de leitura de palavras, indicando o papel relevante da consciência fonológica no desempenho da leitura, particularmente na decodificação de palavras ${ }^{17}$.
A decodificação implica a capacidade de dividir uma palavra em seus sons constituintes, a conversão letra em som e a combinação dos sons da fala para formar uma palavra ${ }^{17-19}$; é considerada uma área crítica para o sucesso no desenvolvimento da aquisição da linguagem da leitura e escrita. Desta forma, escolares que apresentam dificuldades nas habilidades fonológicas vão apresentar também dificuldades para perceber as relações do princípio alfabético do nosso sistema de escrita, ou seja, em aprender as representações de letra e som, e, por conseguinte, terão dificuldades também na ortografia ${ }^{20,21}$.

Para uma leitura competente, deve haver o reconhecimento da palavra de forma rápida e acurada. Essa rapidez na identificação da palavra ocorre devido à formação do léxico mental, em que as palavras familiares e de alta frequência são reconhecidas visualmente, enquanto que a identificação de palavras novas e de baixa frequência depende de estratégias fonológicas, em que o leitor faz a associações das letras aos sons 8,9,12,14,19-23.

O reconhecimento da palavra em um sistema de escrita alfabético pode ser explicado pelo processo da dupla rota, isto é, a leitura pode ocorrer por meio de um processo que envolva mediação fonológica (rota fonológica) ou por meio de um processo visual direto (rota lexical). A leitura pela rota fonológica depende da utilização do conhecimento das regras de conversão entre grafema e fonema para que a construção da pronúncia da palavra possa ser efetuada. É criado, então, um código fonológico com o objetivo de este ser identificado pelo sistema de reconhecimento auditivo de palavras, liberando o significado da palavra. A leitura pela rota lexical depende do reconhecimento de uma palavra previamente adquirida e memorizada no sistema de reconhecimento visual de palavras e na recuperação do significado e da pronúncia dessa palavra por meio de endereçamento direto ao léxico, sendo esta pronúncia obtida como um todo. Assim, palavras de diferentes níveis de regularidade alfabética podem ser lidas sem problemas ${ }^{24}$.

De acordo com a literatura, a melhor maneira de avaliar o reconhecimento das palavras é por meio da aplicação de leitura de palavras reais isoladas, pois desta forma não há sugestões psicolinguísticas, pictóricas ou contextuais, enquanto que para avaliar a decodificação é recomendada a leitura de pseudopalavras, pois esta determina a capacidade que o leitor tem em decodificar palavras que ele não conhece ${ }^{18}$. As pseudopalavras podem ser definidas como segmentos de sílabas e grafemas que fazem parte do sistema linguístico, mas que não possuem significado; são derivadas de palavras reais, modificando-se apenas um ou mais grafemas. 
Diante desse contexto, este estudo teve por objetivos analisar o desempenho de escolares de $2^{\mathrm{a}}$ a $5^{\mathrm{a}}$ série do ensino fundamental em provas de habilidades metalinguísticas e leitura, segundo critérios psicolinguísticos e cognitivo-linguísticos e verificar similaridade e diferenças entre as análises.

\section{MÉTODOS}

Participaram deste estudo experimental de coorte transversal 120 escolares de $2^{\underline{a}}$ a $5^{\underline{a}}$ série do ensino fundamental, sendo 68 escolares do gênero masculino e 52 do gênero feminino, de uma escola pública municipal da cidade de Marília, SP, indicada pelo Núcleo de Apoio Psicopedagógico da Secretaria Municipal de Educação da cidade de Marília/SP, divididos em 4 grupos de 30 alunos cada (descritos na Tabela 1), sendo:

- Grupo I (GI): composto por 30 escolares da $2^{\mathrm{a}}$ série;

- Grupo II (GII): composto por 30 escolares da $3^{a}$ série;

- Grupo III (GIII): composto por 30 escolares da 4⿳亠丷a série;

- Grupo IV (GIV): composto por 30 escolares da 5a série.

Tabela 1 - Distribuição dos escolares pela média de idade e gênero em cada grupo

\begin{tabular}{ccccc}
\hline Grupos & GI & GII & GIII & GIV \\
\hline Média Etária & $8 \mathrm{a} 1 \mathrm{~m}$ & $8 \mathrm{a} 2 \mathrm{~m}$ & $9 \mathrm{a} 7 \mathrm{~m}$ & $11 \mathrm{a} 6 \mathrm{~m}$ \\
Masculino & $17(57 \%)$ & $14(47 \%)$ & $9(63 \%)$ & $18(60 \%)$ \\
Feminino & $13(43 \%)$ & $16(53 \%)$ & $11(37 \%)$ & $12(40 \%)$ \\
\hline
\end{tabular}

Legenda: Gl: escolares da $2^{2}$ série; GII: escolares da $3^{\underline{a}}$ série; GIII: escolares da $4^{\underline{a}}$ série; GIV: escolares da $5^{\underline{a}}$ série.

Como critérios de exclusão foram consideradas: a não assinatura dos pais ou responsáveis pelos alunos no Termo de Consentimento Livre e Esclarecido e a presença de deficiência sensorial, motora ou cognitiva referida em prontuário escolar ou observação do professor. Como critérios de inclusão foram consideradas: a assinatura do Termo de Consentimento Livre e Esclarecido e a ausência de queixa auditiva ou visual descritas nos prontuários escolares ou observação dos professores.

Para a realização deste estudo foram utilizados os seguintes procedimentos:

a) Termo de Consentimento: Conforme resolução do Conselho Nacional de Saúde CNS 196/96, anteriormente ao início das avaliações, os pais ou responsáveis dos pacientes selecionados assinaram o termo de Consentimento Pós-Informado para autorização da realização do estudo.

b) Provas de habilidades metalinguísticas e de leitura de palavras reais e leitura de pseudopalavras do "PROHMELE-Provas de Habilidades Metalinguísticas e de Leitura" ${ }^{25,26 .}$

Foram aplicadas as seguintes provas do Prohmele:

\section{A. Provas de Habilidades Metalinguísticas A.1 - Habilidades silábicas: \\ - Identificação de sílabas inicial (ISI). \\ - Identificação de sílabas final (ISF).}

- Identificação de sílabas medial (ISM).

- Segmentação (Seg_Sil).

- Adição (Ad_Sil).

- Substituição (Subs_Sil).

- Subtração (Subt_Sil).

- Combinação de sílabas (Com_Sil).

A.2 - Habilidades fonêmicas:

- Identificação de fonema inicial (IFI).

- Identificação de fonema final (IFF).

- Identificação de fonema medial (IFM).

- Segmentação (Seg_Fon).

- Adição (Ad_Fon).

- Substituição (Subs_Fon).

- Subtração (Subt_Fon).

- Combinação de fonemas

\section{B. Provas de Leitura}

B.1 - Leitura de palavras reais: foi apresentada lista de palavras reais isoladas (133 palavras).

B.2 - Leitura de pseudopalavras: foi apresentada lista de pseudopalavras (27 pseudopalavras)

A aplicação das provas metalinguísticas de identificação e manipulação foi realizada com a criança sentada em uma cadeira escolar sem material algum de frente para a aplicadora. Durante a realização das provas de habilidades metalinguísticas, a aplicadora ocultou seus lábios com as próprias folhas das provas para que a criança não tivesse pista visual da articulação dos sons produzidos na sua fala. As respostas da criança foram anotadas 
com caneta em folha de respostas do Prohmele. A criança foi instruída e treinada previamente por meio de exemplos similares aos da prova para que soubesse o que deveria fazer.

As provas de leitura foram realizadas em voz alta e gravadas em um aparelho gravador analógico da marca SONY - Cassete-Corder Clear Voice TCM 150 para posterior análise qualitativa. O tempo das provas de leitura de palavras e pseudopalavras foi cronometrado por meio de relógio digital. Cada escolar recebeu instrução de como deveria ler as listas de palavras, apresentadas no formato de letra arial tamanho 14, espaço duplo, divididas em colunas segundo extensão de palavras (monossilábicas, dissilábicas, trissilábicas e polissilábicas -4 a 7 sílabas) e de pseudopalavras (monossilábicas, dissilábicas, trissilábicas). Na prova de leitura de pseudopalavras foi esclarecido aos escolares que estes iriam ler palavras que não existem e que por isto não fazem parte de seu vocabulário.

As provas foram aplicadas individualmente em uma sessão com cerca de 50 minutos. A coleta de dados foi realizada em dois meses, no segundo semestre de 2007, especificamente entre os meses de agosto e setembro.

O número de palavras na prova de leitura de palavras reais e pseudopalavras é diferente devido à primeira lista ser composta de palavras segundo as regras de correspondência grafofonêmica independente do contexto e de correspondência grafofonêmica dependente do contexto, enquanto que a segunda lista apenas foi composta de pseudopalavras derivadas de palavras segundo a regra de correspondência grafofonêmica independente do contexto. Todas as provas deste estudo foram analisadas segundo o critério de erros.

A caracterização dos tipos de erros da leitura de palavras reais e pseudopalavras foi realizada a partir de dois critérios descritos na literatura, a saber:

- Critério 1, baseado nos princípios psicolinguísticos de decodificação das regras do sistema alfabético do português do Brasil, tendo sido utilizadas as seguintes regras ${ }^{27}$ :

- D1 (Regra de correspondência grafofonêmica independente do contexto);

- D2 (Regra de correspondência grafofonêmica dependente do contexto);

- D4 (Valores da letra "X" dependentes exclusivamente do léxico mental e ortográfico).

$\mathrm{Na}$ prova de leitura de pseudopalavras é considerada somente a regra D1, pois seu objetivo é verificar a correspondência unívoca entre letra e som.
- Critério 2, baseado na classificação dos tipos de erros, de acordo com as estratégias cognitivolinguísticas utilizadas na leitura ${ }^{18}$ :

- Para palavras reais:

- regularizações (PR_REG): quando uma palavra irregular é lida como regular.

- palavras visualmente semelhantes (PR_ VS): quando uma palavra é lida como outra que tenha letra(s) semelhante(s).

- tentativas de som mal sucedidas (PR TSMS): quando o escolar tenta usar as representações de letra e som, séries de letras ou outras unidades para emitir palavras que não poderiam ser reconhecidas automaticamente (leitura silabada).

- falha na aplicação de regras ortográficas (PR_FARO): quando a palavra é lida sem que suas diferenças de regras ortográficas sejam reconhecidas.

- recusas (PR_REC): quando o escolar se recusa a ler a palavra.

- Para pseudopalavras:

- Iexicalização (PP_LEX): quando a pseudopalavra é lida como uma palavra real.

- tentativas de som mal sucedidas (PP TSMS): quando o escolar tenta usar as representações de letra e som, séries de letras ou outras unidades para emitir palavras que não poderiam ser reconhecidas automaticamente (leitura silabada).

- falha na aplicação de regras ortográficas (PP_FARO): quando a palavra é lida sem que suas diferenças de regras ortográficas sejam reconhecidas.

- recusas (PP_REC): quando o escolar se recusa a ler a palavra.

Não houve pareamento por gênero, uma vez que as pesquisadoras estavam interessadas no desempenho de todos os escolares que compuseram as salas de aula de $2^{\underline{a}}$ a $5^{\underline{a}}$ série.

Este trabalho foi aprovado pelo Comitê de Ética em Pesquisa da Faculdade de Filosofia e Ciências da Universidade Estadual Paulista - FFC/UNESP/ Marília - SP, sob o protocolo de número 3326/2006.

Para análise estatística foi utilizado o programa SPSS (Statistical Package for Social Sciences), em sua versão 13.0, baseando-se no número de erros apresentados pelos quatro grupos. Os resultados foram analisados estatisticamente por meio do teste de Kruskal-Wallis. O nível de significância foi de 5\% $(0,050)$, ou seja, quando o valor da significância calculada $(p)$ foi menor do que $5 \%(0,050)$, observouse uma diferença dita 'estatisticamente significante' (marcada em asterisco nas tabelas). 


\section{RESULTADOS}

Os dados encontrados revelaram diferenças estatisticamente significantes entre os grupos nas habilidades metalinguísticas silábicas e fonêmicas, com a média estatística diminuindo da $2^{\underline{a}}$ à $5^{\underline{a}}$ série sucessivamente, como mostra a Tabela 2.

As diferenças estatisticamente significantes quanto às regras de decodificação de palavras reais e pseudopalavras são descritas na Tabela 3.

As médias das Tabelas 4 e 5 indicam a frequência de ocorrência de cada tipo de erro segundo o critério 2, desta forma quanto maior a média, mais erros daquele determinado tipo ocorreram, apontando a frequência do erro, ou seja, quanto maior a média, menor o desempenho na leitura de palavras e pseudopalavras para aquele determinado tipo de erro.

Os resultados da prova de leitura de palavras reais, observados na Tabela 4, revelaram que houve diferenças estatisticamente significantes para todas as variáveis na leitura de palavras reais, com exceção do erro tipo Recusas (PR_REC), com médias superiores para Tentativas de Som Mal Sucedidas
(PR_TSMS) e Falha na Aplicação de Regras Ortográficas (PR_FARO) em todos os grupos, indicando que estes tipos de erros foram os de maior ocorrência, sendo constatado, portanto, desempenho inferior dos escolares para estes tipos de erros em relação aos outros tipos.

A Tabela 5 indica os resultados da prova de leitura de pseudopalavras. Na leitura de pseudopalavras houve diferença estatisticamente significante em Tentativas de Som Mal Sucedidas (PP_TSMS), indicando que os escolares apresentaram desempenho inferior na decodificação de palavras que exigiram a utilização de informação fonológica. Para o Gl, as médias superiores foram para Tentativas de Som Mal Sucedidas (PP_TSMS), seguidas de Falha na Aplicação de Regras Ortográficas (PP_FARO), denotando que as regras ortográficas não foram respeitadas e que a decodificação foi realizada pela rota fonológica. Enquanto que para o GII, GIII e GIV, as médias superiores também foram para Tentativas de Som Mal Sucedidas (PP_TSMS) e também para Lexicalização (PP_LEX), indicando que houve lexicalização das pseudopalavras, sugerindo que nestas séries houve a utilização da rota lexical.

Tabela 2 - Distribuição das variáveis com diferenças estatisticamente significantes nas provas de habilidades metalinguísticas de identificação e manipulação de sílabas e fonemas

\begin{tabular}{|c|c|c|c|c|c|c|c|c|}
\hline Variável & Grupo & Média & $\begin{array}{l}\text { Desvio } \\
\text { padrão }\end{array}$ & $\begin{array}{l}\text { Signifi- } \\
\text { cância (p) }\end{array}$ & Variável & Média & $\begin{array}{l}\text { Desvio } \\
\text { padrão }\end{array}$ & $\begin{array}{c}\text { Signifi- } \\
\text { cância }(p)\end{array}$ \\
\hline \multirow{4}{*}{ ISF } & 1 & 2,47 & 1,72 & \multirow{4}{*}{$<0,001^{*}$} & \multirow{4}{*}{ Seg_Sil } & 1,10 & 1,65 & \multirow{4}{*}{$0,010^{*}$} \\
\hline & II & 2,00 & 1,88 & & & 0,33 & 0,84 & \\
\hline & III & 1,07 & 1,36 & & & 0,27 & 0,83 & \\
\hline & IV & 1,00 & 1,29 & & & 0,13 & 0,43 & \\
\hline \multirow{4}{*}{ Ad_Sil } & 1 & 2,00 & 1,89 & \multirow{4}{*}{$0,001^{*}$} & \multirow{4}{*}{ Subt_Sil } & 2,23 & 2,01 & \multirow{4}{*}{$0,004^{*}$} \\
\hline & II & 1,47 & 1,87 & & & 1,73 & 2,08 & \\
\hline & III & 0,97 & 1,85 & & & 1,10 & 1,56 & \\
\hline & IV & 0,60 & 1,16 & & & 0,97 & 1,90 & \\
\hline \multirow{4}{*}{ Sub_Sil } & I & 3,70 & 2,39 & \multirow{4}{*}{$<0,001^{*}$} & & 6,40 & 2,71 & \multirow{4}{*}{$0,021^{*}$} \\
\hline & II & 3,13 & 2,49 & & \multirow{3}{*}{ Sub_Fon } & 6,03 & 2,87 & \\
\hline & III & 2,73 & 2,41 & & & 4,93 & 3,13 & \\
\hline & IV & 1,17 & 1,70 & & & 4,30 & 2,96 & \\
\hline \multirow{4}{*}{ Com_Sil } & 1 & 4,67 & 2,75 & \multirow{4}{*}{$0,011^{*}$} & & 7,97 & 2,83 & \multirow{4}{*}{$0,048^{*}$} \\
\hline & II & 3,60 & 2,67 & & \multirow{3}{*}{ Com_Fon } & 7,17 & 3,49 & \\
\hline & III & 3,20 & 2,61 & & & 6,53 & 4,05 & \\
\hline & IV & 2,60 & 2,72 & & & 5,37 & 3,80 & \\
\hline
\end{tabular}

Legenda: Identificação Sílaba Final; Seg Sil, Segmentação Silábica; Ad Sil, Adição Sílabas; Subt Sil, Subtração Sílabas; Sub Sil, Substituição Sílabas; Sub Fon, Substituição Fonemas; Com Sil, Combinação de Sílabas; Com Fon, Combinação de Fonemas.

Teste: Kruskal-Wallis

p-valor: $<0,050$ 
Tabela 3 - Distribuição das variáveis com diferenças estatisticamente significantes para as regras de decodificação de palavras reais e pseudopalavras, de acordo com o critério 1

\begin{tabular}{ccccccccc}
\hline Variável & Grupo & Média & $\begin{array}{c}\text { Desvio } \\
\text { padrão }\end{array}$ & $\begin{array}{c}\text { Signifi- } \\
\text { cância (p) }\end{array}$ & Variável & Média & $\begin{array}{c}\text { Desvio } \\
\text { padrão }\end{array}$ & $\begin{array}{c}\text { Signifi- } \\
\text { cância }(\mathbf{p})\end{array}$ \\
\hline \multirow{2}{*}{ D1_PP } & I & 10,60 & 8,12 & & & 19,13 & 18,50 & \\
& II & 6,47 & 6,21 & $0,010^{*}$ & & 9,77 & 7,49 & $<0,001^{*}$ \\
& III & 4,70 & 2,68 & & D1_PR & 5,93 & 6,48 & \\
\hline \multirow{2}{*}{ D2_PR } & IV & 5,57 & 4,97 & & & 6,53 & 8,38 & \\
& I II & 3,40 & 1,50 & & & 4,00 & 1,02 & \\
& III & 1,93 & 1,34 & & & 3,67 & 1,30 & $0,000^{*}$ \\
\hline
\end{tabular}

Legenda: Regras Scliar - Cabral: D1_PP: Regras de correspondência grafofonêmicas independentes do contexto grafêmico para a leitura de pseudopalavras; D1_PR: Regras de correspondência grafofonêmicas independentes do contexto grafêmico para a leitura de palavras reais; D2_PR: Regras de correspondência grafofonêmicas dependentes do contexto grafêmico para a leitura de palavras reais; D4_PR: Regras de correspondência grafofonêmicas dependentes do contexto morfossintático.

Teste: Kruskal-Wallis

p-valor: $<0,050$

Tabela 4 - Descrição dos resultados segundo o critério 2, indicando a distribuição das médias, desvio padrão, valores de referência mínimo e máximo e p-valor para as variáveis da prova de leitura de palavras reais

\begin{tabular}{|c|c|c|c|c|c|c|c|}
\hline Variável & Grupo & $\mathbf{n}$ & Média & $\begin{array}{l}\text { Desvio } \\
\text { padrão }\end{array}$ & Min & $\operatorname{Max}$ & Significância (p) \\
\hline \multirow{4}{*}{ PR_VS } & $I$ & 30 & 9,47 & 12,99 & 0,00 & 69,00 & \multirow{4}{*}{$0,004^{*}$} \\
\hline & II & 30 & 5,80 & 3,80 & 1,00 & 16,00 & \\
\hline & III & 30 & 4,00 & 3,61 & 0,00 & 14,00 & \\
\hline & IV & 30 & 4,40 & 6,21 & 0,00 & 34,00 & \\
\hline \multirow{4}{*}{ PR_REG } & $I$ & 30 & 7,13 & 4,17 & 0,00 & 20,00 & \multirow{4}{*}{$<0,001^{*}$} \\
\hline & II & 30 & 5,10 & 2,80 & 1,00 & 11,00 & \\
\hline & III & 30 & 3,07 & 2,20 & 0,00 & 8,00 & \\
\hline & IV & 30 & 3,53 & 3,00 & 0,00 & 12,00 & \\
\hline \multirow{4}{*}{ PR_TSMS } & $I$ & 30 & 27,07 & 19,60 & 4,00 & 69,00 & \multirow{4}{*}{$<0,001^{*}$} \\
\hline & II & 30 & 17,87 & 17,39 & 1,00 & 95,00 & \\
\hline & III & 30 & 8,93 & 7,47 & 0,00 & 31,00 & \\
\hline & IV & 30 & 11,00 & 11,13 & 0,00 & 52,00 & \\
\hline \multirow{4}{*}{ PR_FARO } & $I$ & 30 & 11,27 & 4,56 & 4,00 & 20,00 & \multirow{4}{*}{$<0,001^{*}$} \\
\hline & II & 30 & 9,07 & 4,30 & 0,00 & 18,00 & \\
\hline & III & 30 & 4,97 & 3,79 & 0,00 & 15,00 & \\
\hline & IV & 30 & 6,93 & 5,60 & 0,00 & 28,00 & \\
\hline \multirow{4}{*}{ PR_REC } & $I$ & 30 & 1,67 & 8,20 & 0,00 & 45,00 & \multirow{4}{*}{0,090} \\
\hline & II & 30 & 1,00 & 2,49 & 0,00 & 11,00 & \\
\hline & III & 30 & 0,57 & 2,16 & 0,00 & 9,00 & \\
\hline & IV & 30 & 0,17 & 0,75 & 0,00 & 4,00 & \\
\hline
\end{tabular}

Legenda: regularizações (PR_REG),palavras visualmente semelhantes (PR_VS), tentativas de som mal sucedidas (PR_TSMS), falha na aplicação de regras ortográficas (PR_FARO), recusas (PR_REC).

Teste: Kruskal-Wallis

p-valor: $<0,050$ 
Tabela 5 - Descrição dos resultados segundo o critério 2, indicando a distribuição das médias, desvio padrão, valores de referência mínimo e máximo e p-valor para as variáveis da prova de leitura de pseudopalavras

\begin{tabular}{cccccccc}
\hline Variável & Grupo & $\mathbf{n}$ & Média & $\begin{array}{c}\text { Desvio } \\
\text { padrão }\end{array}$ & Min & Max & Significância (p) \\
\hline \multirow{2}{*}{ PP_LEX } & I & 30 & 2,90 & 1,52 & 0,00 & 6,00 & \\
& II & 30 & 3,10 & 1,99 & 0,00 & 9,00 & 0,598 \\
& III & 30 & 2,47 & 1,36 & 0,00 & 5,00 & \\
PP_TSMS & IV & 30 & 2,80 & 1,86 & 0,00 & 8,00 & \\
& I & 30 & 9,20 & 9,89 & 0,00 & 40,00 & \\
& II & 30 & 4,53 & 6,97 & 0,00 & 37,00 & \multirow{2}{*}{$0,042^{*}$} \\
PP_FARO & III & 30 & 4,17 & 3,46 & 0,00 & 16,00 & \\
& IV & 29 & 4,38 & 5,31 & 0,00 & 26,00 & \\
& I & 30 & 3,37 & 2,74 & 0,00 & 13,00 & \\
& II & 30 & 2,40 & 2,08 & 0,00 & 10,00 & \\
PP_REC & III & 30 & 1,83 & 1,37 & 0,00 & 4,00 & \\
& IV & 30 & 2,30 & 1,39 & 0,00 & 5,00 & \\
& I & 30 & 0,00 & 0,00 & 0,00 & 0,00 & \\
& II & 30 & 0,03 & 0,18 & 0,00 & 1,00 & \\
\hline
\end{tabular}

Legenda: lexicalização (PP_LEX), tentativas de som mal sucedidas (PP_TSMS), falha na aplicação de regras ortográficas (PP_ FARO), recusas (PP_REC).

Dados analisados estatisticamente por meio do Teste de Kruskal-Wallis.

Teste: Kruskal-Wallis

p-valor: $<0,050$

\section{DISCUSSÃO}

Os resultados das provas metalinguísticas revelaram que os desempenhos nas tarefas silábicas foram superiores aos das tarefas fonêmicas nos quatro grupos estudados, GI, GII, GIII e GIV, dados que corroboram estudos anteriores, em que também houve um desempenho superior nas tarefas silábicas em relação às fonêmicas ${ }^{7}$. A literatura relata que a consciência de sílabas é adquirida mais precocemente porque a percepção de unidades maiores, como as sílabas, é mais perceptível $\mathrm{e}$, por isso, mais facilmente manipulada ${ }^{13}$. Esses resultados também podem ser explicados devido à manipulação de sílabas ser uma atividade bastante comum nas escolas, não ocorrendo o mesmo com a manipulação de fonemas, o que pode justificar a dificuldade das crianças em lidar com esta habilidade, havendo, assim, diferentes níveis de consciência fonológica para diferentes tarefas, sugerindo que a consciência silábica desenvolve-se antes da fonêmica. Isso também pode ser justificado devido à sílaba conter um núcleo vocálico que é caracterizado por um pico de energia acústica que age como pista auditiva, facilitando a localização dos segmentos silábicos pelas crianças ${ }^{2,8-13}$.

$\mathrm{Na}$ comparação do desempenho das tarefas silábicas e das tarefas fonêmicas entre as séries, foi observado que o desempenho das tarefas silábicas e o das fonêmicas tornaram-se superiores com a escolarização, conforme citado na literatura, o que sugere uma relação de reciprocidade entre o aprendizado da linguagem escrita e as habilidades fonológicas, havendo influência entre consciência fonológica e aquisição da escrita e diferentes níveis e habilidades em consciência fonológica, que são aprimorados a partir da exposição sistemática à escrita ${ }^{11-16}$.

Estudos anteriores consideraram que um maior nível de escolaridade está relacionado a uma maior proficiência em leitura, o que pode proporcionar um melhor desempenho em tarefas que avaliem habilidades linguísticas. Neste estudo, todos os grupos apresentaram desempenho inferior em manipulação fonêmica, inclusive a quarta e quinta séries, o que pode ser explicado por estas últimas séries 
já terem maior contato com a ortografia e terem se baseado na forma escrita e não nos sons.

De acordo com a literatura ${ }^{13}$, algumas tarefas de consciência fonológica são mais simples, exigindo apenas uma operação seguida de resposta, como a segmentação de sílabas de uma palavra. Entretanto, tarefas mais complexas exigem a realização de duas operações, ou seja, guardar uma unidade na memória enquanto é feita uma nova operação. Além disso, as respostas variam de acordo com o tipo de operação que é exigido da criança. Estes aspectos parecem explicar os resultados deste estudo quanto ao desempenho inferior nas tarefas de manipulação tanto silábica como fonêmica.

Os resultados nas provas de leitura de palavras reais e de pseudopalavras, segundo o critério 1 (regras de decodificação do sistema de escrita do português do Brasil) ${ }^{27}$, indicaram que, para a regra D1 PP e D1_PR, as respostas incorretas diminuíram do GI para o GIII, tendo aumentado no GIV. O número de respostas incorretas do GI foi maior em relação a todos os grupos, havendo pequena diferença entre o GIII e GIV, sugerindo que, nas últimas séries, não há mudanças na apreensão dessas regras. Apesar de as respostas incorretas decaírem do GI ao GIV, observa-se que do Gl ao GIII houve certa regularidade no decréscimo dessas medidas, porém do GIII ao GIV ocorre o contrário, ou seja, há um aumento destas respostas, indicando que este último grupo apresentou mais erros na decodificação destas regras que o anterior.

O desempenho da quinta série na decodificação das regras D1 e D2 pode ser explicado pelo fato de que com a escolarização ocorre uma mudança no uso das rotas de processamento da leitura, sendo que, nas séries iniciais, a decodificação exige o uso da rota fonológica, depois, quando esta habilidade já está mais consolidada, o processo de decodificação fonológica contribui para que a criança forme a representação ortográfica da nova palavra, permitindo que esta nova palavra seja lida pela rota lexical e a decodificação passe a ser mais rápida, uma vez que o processo fonológico permitirá à criança realizar a leitura pela rota lexical. $\mathrm{O}$ uso da rota lexical pode ter provocado mais erros na decodificação desta regra na quinta série ${ }^{20}$.

Na regra D4, que constitui os valores da letra " $x$ ", as respostas incorretas diminuíram sucessivamente do GI ao GIV. No entanto, apesar de os erros diminuírem no GIV, estes ainda apareceram, denotando uma incompleta apropriação desta regra, talvez por estas crianças terem um maior contato com a linguagem escrita somente na escola, visto que esta regra depende de uma formação do léxico mental ortográfico, que ocorre com repetidas exposições às palavras que contêm estas regras ${ }^{27,28}$.
Os resultados apresentados pelo GIV indicaram que, com a escolarização e o desenvolvimento, a criança apreende e estabiliza as relações ortográficas, o que permite a recuperação automática e adequada da palavra e conduz ao uso menos frequente da rota fonológica. Na tentativa de recuperar a palavra diretamente do léxico, deixam de regularizá-la e segmentá-la, buscando palavras com estrutura fonológica similar. Assim, os dados dessa pesquisa sugerem que, quando se depara com uma palavra com estrutura ortográfica familiar, a criança tenta lê-la pela rota lexical, ocorrendo os erros, pois, na troca por uma palavra similar, as regras não são decodificadas ${ }^{21}$.

Os resultados sugeriram uma relação entre a habilidade de manipulação fonêmica com a apreensão das regras, visto que no GIV as dificuldades nestas tarefas persistem, indicando relação entre as habilidades fonológicas e a aprendizagem de regras ortográficas ${ }^{29}$.

$\mathrm{Na}$ análise dos dados segundo o critério 2 (classificação dos tipos de erros na leitura) ${ }^{18}$, pode-se verificar na leitura de palavras reais que em todos os grupos as médias superiores foram para Tentativas de Som Mal Sucedidas (PR_TSMS) e Falha na Aplicação de Regras Ortográficas (PR_FARO), seguidas de Palavras Visualmente Semelhantes (PR_VS), Regularizações (PR_REG) e Recusas (PR_REC), indicando a ordem da ocorrência dos tipos de erros. As médias tornaram-se inferiores do GI ao GIII para todos os tipos de erros, com exceção do erro tipo Recusas (PR_REC), cuja média foi se tornando inferior da $2^{\underline{a}}$ até a $5^{\underline{a}}$ série, indicando que com a seriação os escolares apresentam menos recusas em ler palavras novas e desconhecidas.

O maior número de erros na leitura de palavras reais foi para o tipo Falha na Aplicação de Regras Ortográficas (FARO) e para o tipo Tentativas de Som Mal Sucedidas (TSMS), atribuídos respectivamente às dificuldades de aplicação das regras ortográficas e às dificuldades no processo fonológico subjacentes à leitura, estes achados corroboraram estudo anterior ${ }^{29}$.

$\mathrm{Na}$ análise dos dados na leitura de pseudopalavras, de acordo com o critério $2{ }^{18}$, foi possível verificar que o $\mathrm{Gl}$ apresentou média superior em Tentativas de Som Mal sucedidas (PP_TSMS), seguida de Falha na Aplicação de Regras Ortográficas (PP_FARO), Lexicalização (PP_LEX) e Recusas (PP_REC), indicando que o desempenho foi se tornando progressivamente superior de Tentativas de Som Mal Sucedidas (PP_TSMS) até Recusas (PP_REC), em que este grupo apresentou o menor número de erros. Enquanto que para o GII, GIII e GIV as médias superiores foram também para Tentativas de Som Mal Sucedidas (PP_TSMS), 
seguidas depois, em ordem decrescente, de Lexicalização (PP_LEX), Falha na Aplicação de Regras Ortográficas (PP_FARO) e Recusas (PP_REC). Estes resultados indicaram que a $3^{a}, 4^{\underline{a}}$ e $5^{\text {a }}$ séries também apresentaram dificuldades nos erros do tipo Tentativas de Som Mal Sucedidas (PP_TSMS), sendo este o mais frequente. No entanto, os erros do tipo Falha na Aplicação de Regras Ortográficas (PP_FARO) ficaram depois de Lexicalização (PP_ LEX), indicando que nestas séries houve menos dificuldades para lidar com as regras ortográficas, mas que houve mais lexicalização das pseudopalavras. Entretanto, a $2^{2}$ série apresentou como erro de segunda maior ocorrência o tipo Falha na Aplicação de Regras Ortográficas (PP_FARO), sugerindo que nesta série os escolares apresentam desempenho inferior ao lidar com regras ortográficas.

Neste estudo, assim como em estudo anterior ${ }^{29}$, os tipos de erros Tentativas de Som Mal Sucedidas (TSMS) e Falha na Aplicação de Regras Ortográficas (FARO) para a leitura de pseudopalavras eram esperados, já que também apareceram na leitura de palavras conhecidas.

Os resultados apontaram que, na leitura de palavras reais, de acordo com o critério 2 , o desempenho foi se tornando progressivamente superior do GI para o GIII, no entanto passou a ser inferior deste grupo para o GIV em todas as variáveis, ocorrendo o mesmo na leitura de pseudopalavras nos tipos de erros Tentativas de Som Mal Sucedidas (PP_TSMS) e Falha na Aplicação de Regras Ortográficas (PP_FARO). Esses resultados sugerem que os escolares da $5^{\text {a }}$ série tiveram desempenho inferior em relação às outras séries, porque suas dificuldades relacionadas ao processamento fonológico podem ter interferido na formação de um léxico ortográfico, prejudicando a leitura pela rota lexical. O mesmo resultado ocorreu em relação ao critério 1 , com as dificuldades apresentadas nas provas de habilidades metalinguísticas, interferindo na decodificação das regras. Assim, os resultados apresentados nesta análise (critério 2) confirmam os resultados obtidos na análise pelo critério 1, ou seja, o desempenho inferior para os tipos de erros Tentativas de Som Mal Sucedidas (PP_TSMS) e Falha na Aplicação de Regras Ortográficas (PP_ FARO) atribuídos, respectivamente, às dificuldades de aplicação das regras ortográficas e às dificuldades no processo fonológico subjacente à leitura, se relaciona com os resultados obtidos na análise pelo critério 1, cujos resultados indicaram que as dificuldades encontradas na execução das tarefas estão relacionadas com as dificuldades destes escolares em habilidades de processamento fonológico e na decodificação das regras ${ }^{25,26,29}$, sugerindo uma relação entre as habilidades fonológicas e a aprendizagem de regras ortográficas.

O desempenho inferior do GIV em relação aos outros grupos, tanto em uma análise como na outra, sugeriu um maior uso da rota lexical, pois, ao fazer uso de uma decodificação direta, as regras ortográficas não foram respeitadas, uma vez que estes escolares apresentaram dificuldades de manipulação fonêmica, não tendo construído, assim, um léxico ortográfico necessário para a leitura por via direta.

Problemas com o desenvolvimento da habilidade fonológica da linguagem oral e pouco envolvimento do meio com a leitura são características comuns de escolares que não respondem à instrução de leitura, enquanto que escolares com fortes habilidades de linguagem oral podem ser mais hábeis para compensar outras fragilidades em habilidades para a leitura como consciência fonológica, decodificação ou compreensão que os escolares com habilidades pouco desenvolvidas. Quando o escolar se torna consciente da palavra melhora seu vocabulário e sua compreensão, o que proporciona, por sua vez, melhora nas habilidades de processamento fonológico ${ }^{30,31}$. Os escolares se tornam mais hábeis em decodificar novas palavras usando a relação letra/som, usando esta conversão para ajudá-los a ler palavras desconhecidas ${ }^{19,23,32-35}$.

Estudos anteriores indicaram que existe uma importante e recíproca influência entre os diferentes níveis de habilidades fonológicas e aquisição da escrita que são aprimorados a partir da exposição sistemática à escrita. Além do papel de reciprocidade entre a habilidade fonológica e o desenvolvimento da leitura e escrita, estes estudos também verificaram que a média dos aspectos avaliados em consciência fonológica aponta para o papel da escolaridade como favorecedor ${ }^{2,13}$.

Os escolares formam representações na memória depois que eles identificam as palavras corretamente várias vezes. Estas representações são criadas rapidamente pela maioria dos escolares que são hábeis em usar a consciência dos sons dentro da palavra para ajudá-los a recuperar sua ortografia. Em contraste, escolares que não desenvolvem boas habilidades de processamento fonológico têm mais dificuldades em reconhecer palavras isoladas, o que proporciona dificuldades para formar representações das palavras na memória para que - leitor possa reconhecer a palavra rapidamente 32. Com a seriação, ocorre uma mudança no uso das rotas de processamento da leitura, sendo que nas séries iniciais a decodificação exige o uso da rota fonológica, depois, quando esta habilidade já está mais consolidada, o processo de decodificação fonológica contribui para que a criança forme 
a representação ortográfica da nova palavra, permitindo que esta nova palavra seja lida pela rota lexical e o reconhecimento desta passa a ser mais rápido ${ }^{20}$, o que pode ter provocado mais erros do tipo TSMS E FARO na leitura de palavras reais como também a não decodificação das regras D1, D2 e D4, sugerindo que estes escolares estão apresentando dificuldades em palavras que dependem do processamento fonológico para sua decodificação, como também tiveram dificuldades em decodificar palavras que necessitam de conhecimento das regras ortográficas, as quais dependem, por sua vez, de um bom processamento fonológico.

Tanto na leitura de palavras reais como nas pseudopalavras, todos os grupos apresentaram desempenho superior para o tipo de erro Recusas (REC) em relação aos outros tipos de erros, indicando que apesar de cometerem erros ou apresentarem dificuldades, os escolares não evitaram a decodificação de palavras novas ou desconhecidas.

\section{CONCLUSÃO}

Os dados encontrados permitiram concluir que houve relação entre as habilidades metalinguísticas e a leitura; as habilidades metalinguísticas para as sílabas são adquiridas antes das habilidades fonêmicas; as habilidades de identificação são adquiridas anteriormente às habilidades de manipulação; existem níveis diferenciados de desenvolvimento dessas habilidades; os escolares tiveram desempenho superior nas habilidades metalinguísticas com a escolarização, sugerindo uma relação de causalidade recíproca entre estas habilidades e a aprendizagem da linguagem escrita.

Os escolares de todas as séries deste estudo apresentaram desempenho inferior, tanto na leitura de palavras reais como para pseudopalavras, para os erros do tipo tentativas de som mal sucedidas e do tipo falhas na aplicação de regras ortográficas em comparação aos outros tipos de erros. Esses resultados indicam dificuldades na informação fonológica e na utilização das regras ortográficas, visto que estes tipos de erros estão relacionados a estes processos, o que pode ter influenciado no desempenho para a decodificação de palavras e pseudopalavras.

Houve, também, dificuldades na decodificação das regras D1, D2 e D4, sugerindo que estes escolares estão apresentando dificuldades em palavras que dependem do processamento fonológico para sua decodificação, como também tiveram dificuldades em decodificar palavras que necessitam de conhecimento das regras ortográficas, as quais dependem, por sua vez, de um bom processamento fonológico. Este desempenho indica que as dificuldades relacionadas ao processamento fonológico apresentadas por estes grupos podem ter interferido na formação de um léxico ortográfico.

A análise pelo critério 1 fornece dados mais precisos com relação à decodificação das regras ortográficas, sejam de correspondência grafofonêmica independentes de contexto (D1) ou dependentes do contexto grafêmico (D2), bem como dos valores da letra $x$ (D4), indicando o desempenho do escolar quanto às regularidades e irregularidades do sistema de escrita do português do Brasil, o que fornece também a rota de leitura utilizada.

A análise da regra D1 fornece dados quanto ao processamento da correspondência fonemagrafema, indicando como o escolar está utilizando sua habilidade fonológica. A análise das regras D2 e D4 fornece dados quanto ao processamento ortográfico. A análise pelo critério 2 fornece dados em relação ao tipo de erro apresentado pelo escolar, o que indica as estratégias de leitura utilizadas, apontando, assim, a habilidade em que há mais dificuldade, seja de ordem visual, fonológica ou ortográfica, sugerindo também a rota de leitura utilizada.

Ambos os critérios fornecem subsídios para a compreensão de como o escolar está processando os complexos princípios do sistema de escrita do português do Brasil, que, uma vez incorporados, serão constituídos em um importante instrumento para recortar, de forma consciente, a cadeia de fala em unidades menores que a sílaba, contribuindo na relação de reciprocidade entre o desenvolvimento das habilidades metalinguísticas e o desenvolvimento da linguagem escrita, auxiliando na formação de um léxico mental ortográfico.

Os resultados apontam para a importância da adoção de critérios psicolinguísticos ou cognitivolinguísticos na avaliação da leitura de palavras e pseudopalavras, pois estes critérios, juntamente com a avaliação das habilidades metalinguísticas, podem oferecer suporte necessário à compreensão das dificuldades específicas apresentadas pelos escolares, fornecendo ao profissional fonoaudiólogo subsídios que o oriente em relação aos objetivos precisos no atendimento a estes escolares, entretanto, este é um ponto que se encontra em investigação pelos autores deste estudo e será tema de futuras publicações. 


\section{ABSTRACT}

Purpose: to analyze the performance of the metalinguistic skills and reading tests in students from $2^{\text {nd }}$ to $5^{\text {th }}$ grades of elementary education, according to psycholinguistic and cognitive-linguistic criteria and to check similarities and differences between the analyses. Methods: 120 students from $2^{\text {nd }}$ to $5^{\text {th }}$ grades of a municipal school, of both genders, in the age ranging from 7 to 12 year old, divided into 4 groups for each grade. The students were submitted to tests of metalinguistic skills and reading Results: there were statistically significant differences among the groups in the metalinguistic skills, in the decoding of real words and non-words, for each variable, with exception for the 'Refusal' mistake type, with superior average for the types related to unsuccessful sound attempts and failure in the use of orthography, indicating that these types of mistakes were of larger occurrence. In the non-words reading there were statistically significant differences in unsuccessful sound attempts indicating that the students had lower performance in the decoding of words that demanded the use of phonological information. Conclusion: the adoption of the psycholinguistic and cognitive-linguistic criteria in evaluating real words and non-words' reading, along with the evaluation of the metalinguistic skills provide subsidies to the understanding of the way the students were processing the complex writing system of Brazilian Portuguese, besides to giving the necessary support to the comprehension of the specific difficulties showed by the students, guiding the speech and language professional in relation to the direct purposes in their work.

KEYWORDS: Reading; Evaluation; Learning; Linguistics; Education

\section{REFERÊNCIAS}

1. Barrera SD, Maluf MR. Consciência metalinguística e alfabetização: um estudo com crianças da primeira série do ensino fundamental. Psicol Reflex Crit. 2003; 16(3):491-502.

2. Gindri G, Keske-Soares M, Mota HB. Memória de trabalho, consciência fonológica e hipótese de escrita. Pró-Fono. 2007; 19(3):313-22.

3. Santos RM, Siqueira M. Consciência fonológica e memória. Fono Atual. 2002; 5(20):48-53.

4. Freitas GCM. Consciência fonológica e aquisição da escrita: um estudo longitudinal. [tese]. Porto Alegre (RS): Pontifícia Universidade Católica do Rio Grande do Sul; 2003.

5. Paes CTS, Pessoa ACRG. Habilidades fonológicas em crianças não alfabetizadas e alfabetizadas. Rev. CEFAC. 2005; 7(2):149-57.

6. Paula GR, Mota HB, Keske-Soares MA. A terapia em consciência fonológica no processo de alfabetização. Pró-Fono. 2005; 17(2):175-84.

7. Queiroga BAM, Borba DM, Vogeley ACE. Habilidades metalinguísticas e a apropriação do sistema ortográfico. Rev Soc Bras Fonoaudiol. 2005; 9(2):73-80.

8. Cárnio MS, Stivanin L, Vieira MP, Amaro L, Martins VO, Carvalho E, et al. Habilidades de consciência fonológica e letramento em crianças do ensino fundamental. Rev Soc Bras Fonoaudiol. 2006; 11(4):231-42.
9. Cárnio MS, Santos D. Evolução da consciência fonológica em alunos de ensino fundamental. PróFono. 2005; 17(2):195-200.

10. Moojen S, Lamprecht R, Santos RM, Freitas GM, Brodacz R, Siqueira M, et al. Confias - Consciência fonológica: instrumento de avaliação sequencial. São Paulo: Casa do Psicólogo; 2003.

11. Nunes C, Frota S, Mousinho R. Consciência fonológica e o processo de aprendizagem de leitura e escrita: implicações teóricas para o embasamento da prática fonoaudiológica. Rev. CEFAC. 2009 Abr-Jun; 11(2):207-12. http://dx.doi.org/10.1590/ S1516-184620090002000005

12. Gray A, McCutchen D. Young readers' use of phonological information: phonological awareness, memory and comprehension. J Learn Disabil. 2006; 39(4):325-33.

13. Tirapegui CJC, Gajardo LRC, Ortiz ZDB. Conciencia fonológica y lengua en niños con trastorno específico del lenguaje expresivo. Rev. CEFAC. 2005; 7(4):419-25.

14. Salgado CA, Capellini SA. Programa de remediação fonológica em escolares com dislexia do desenvolvimento. Pró-Fono. 2008; 20(1):31-6.

15. Gindri G, Keske-Soares M, Mota HB. Comparação do desempenho de crianças préescolares e de primeira série em tarefas envolvendo a memória de trabalho. Rev Soc Bras Fonoaudiol. 2005; 10(4):201-6. 
16. Algozzine B, McQuiston K, O'Shea D, McCollin $\mathrm{M}$. Improving phonological awareness and decoding skills of high schools students from diverse backgrounds. Prev Sch Failure. 2008; 52(2):67-70.

17. Cirino PT, Israelian MK, Morris MK, Morris RD. Evaluation of the double-deficit hypothesis in college students referred for learning difficulties. J Learn Disabil. 2005; 38(1):29-43.

18. Goulandris NK. Avaliação das habilidades de leitura e ortografia. In: Snowling $M$, Stackhouse J. Dislexia, fala e linguagem. São Paulo: Artmed; 2004. p.91-120.

19. Harn BA, Linan-Thompson S, Roberts G. Intensifying instruction: does additional instructional time make a difference for the most at-risk first graders? J Learn Disabil. 2008; 41(2):115-25.

20. Salgado CA, Capellini SA. Desempenho em leitura e escrita de escolares com transtornos fonológicos. Psicol Esc Educ. 2004; 8(2):179-88. 21. Stivanin L, Scheuer Cl. Tempo de latência para a leitura: influência da frequência da palavra escrita e da escolarização. Rev Soc Bras Fonoaudiol. 2007; 12(3):206-13.

22. Britto DBO, Castro CD, Gouvêa FG, Silveira OS. A importância da consciência fonológica no processo de aquisição e desenvolvimento da linguagem escrita. Rev Soc Bras Fonoaudiol. 2006; 11(3):142-50.

23. Harn BA, Stoolmiller M, Chard DJ. Measuring the dimensions of alphabetic principle on the reading development of first graders: the role of automaticity and unitization. J Learn Disabil. 2008; 41(2):143-57. 24. Pinheiro AMV. Leitura e escrita: uma abordagem cognitiva. Campinas: Psy II; 1994.

25. Cunha VLO. Desempenho de escolares de $1^{\underline{a}}$ a $4^{\mathrm{a}}$ séries em provas de habilidades metalinguísticas e de leitura (PROHMELE). [dissertação]. Marília (SP): Universidade Estadual Paulista; 2008.

26. Cunha, VLO, Capellini, SA. Provas de habilidades metalinguísticas e de leitura-PROHMELE. Rio de Janeiro: Revinter; 2009.
27. Scliar-Cabral L. Princípios do sistema alfabético do português do Brasil. São Paulo: Contexto; 2003. 28. Capellini SA. Dificuldade escolar e distúrbios de aprendizagem: aspectos preventivos e remediativos. In: Valle LELR, organizador. Temas multidisciplinares de neuropsicologia e aprendizagem. Ribeirão Preto: Científica; 2004.

29. Ramos CS. Avaliação de leitura em escolares com indicação de dificuldade de leitura e escrita [dissertação]. São Paulo (SP): Universidade Federal de São Paulo; 2005.

30. Fuchs D, Fuchs LS. Peer-assisted learning strategies: promoting word recognition, fluency, and reading comprehension in young children. J Spec Educ. 2005; 39(1):34-44.

31. Chard DJ, Stoolmiller M, Harn BA, Wanzek J, Vaughn S, Linan-Thompson S, et al. Predicting reading success in a multilevel schoolwide reading model: a retrospective analysis. J Learn Disabil. 2008; 41(2):174-88.

32. Al Otaiba S, Fuchs D. Characteristics of children who are unresponsive to early literacy intervention: a review of the literature. Remed Spec Educ. 2002; 23(5):300-16.

33. Al Otaiba S, Connor C, Lane H, Kosanovich ML, Schatschneider C, Dyrlund AK, et al. Reading first kindergarten classroom instruction and students' growth in phonological awareness and letter naming-decoding fluency. J Sch Psychol. 2008; 46(3):281-314.

34. Kamps D, Abbott M, Greenwood C, Wills H, Veerkamp M, Kaufman J. Effects of small-group reading instruction and curriculum differences for students most at risk in kindergarten: two-year results for secondary - and tertiary-level interventions. J Learn Disabil. 2008; 41(2):101-14.

35. Phillips BM, Clancy-Menchetti J, Lonigan CJ. Successful phonological awareness instruction with preschool children. Top Early Child Spec Educ. 2008; 28(1):3-17. http://dx.doi. org/10.1177/0271121407313813

DOI: 10.1590/S1516-18462010005000017

RECEBIDO EM: 13/08/2009

ACEITO EM: 16/11/2009

Endereço para correspondência:

Vera Lúcia Orlandi Cunha

Rua Clóvis de Camargo Bueno, 218

Palmital - SP

CEP: 19970-000

E-mail: verafono@uol.com.br 